\title{
Ulcerative Proctitis, Rectal Prolapse, and Intestinal Pseudo-Obstruction in Transgenic Mice Overexpressing Hepatocyte Growth Factor/Scatter Factor
}

\author{
Hisashi Takayama, Hitoshi Takagi, William J. LaRochelle, Raj P. Kapur, and \\ Glenn Merlino
}

First Department of Internal Medicine (HT, HT), Gunma University School of Medicine, Maebashi, Gunma, Japan; Laboratory of Molecular Biology (GM) and Laboratory of Cellular and Molecular Biology (WJL), National Cancer Institute, Bethesda, Maryland; and Department of Pathology (RPK), University of Washington Medical Center, Seattle, Washington

\begin{abstract}
SUMMARY: Hepatocyte growth factor/scatter factor (HGF/SF) can stimulate growth of gastrointestinal epithelial cells in vitro; however, the physiological role of HGF/SF in the digestive tract is poorly understood. To elucidate this in vivo function, mice were analyzed in which an HGF/SF transgene was overexpressed throughout the digestive tract. Nearly a third of all HGF/SF transgenic mice in this study ( 28 of 87 ) died by 6 months of age as a result of sporadic intestinal obstruction of unknown etiology. Enteric ganglia were not overtly affected, indicating that the pathogenesis of this intestinal lesion was different from that operating in Hirschsprung's disease. Transgenic mice also exhibited a rectal inflammatory bowel disease (IBD) with a high incidence of anorectal prolapse. Expression of interleukin-2 was decreased in the transgenic colon, indicating that HGF/SF may influence regulation of the local intestinal immune system within the colon. These results suggest that HGF/SF plays an important role in the development of gastrointestinal paresis and chronic intestinal inflammation. HGF/SF transgenic mice may represent a useful model for the study of molecular mechanisms associated with a subset of IBD and intestinal pseudo-obstruction. Moreover, our data identify previously unappreciated side effects that may be encountered when using HGF/SF as a therapeutic agent. (Lab Invest 2001, 81:297-305).
\end{abstract}

$H$ epatocyte growth factor/scatter factor (HGF/ SF) was first identified as a highly potent hepatocyte mitogen (Gohda et al, 1988; Nakamura et al, 1989) but is now known as a multifunctional cytokine based on its ability to stimulate proliferation, movement, and/or morphogenesis of a broad spectrum of cultured epithelial cells expressing the tyrosine kinase receptor encoded by the c-met proto-oncogene (Gherardi and Stoker, 1991; Montesano et al, 1991; Rosen et al, 1994; Rubin et al, 1991; Vande Woude, 1992; Zarnegar and Michalopoulos, 1995). HGF/SF is produced in cells of mesenchymal origin, whereas c-met is expressed in adult and embryonic epithelium, implicating HGF/SF-Met signal transduction pathways as important in the epithelial-mesenchymal interaction that occurs during embryogenesis, tissue organization, and organogenesis. Gene targeting studies have shown that HGF/SF-Met signaling is required for the normal development of liver, skeletal muscle, and

Received August 24, 2000.

This work was supported in part by grants from the Ministry of Education, Science and Culture, Japan (HT, HT), and by NIH DK52530 (RPK).

Address reprint requests to: Dr. Glenn Merlino, Chief, Molecular Genetics Section, Laboratory of Molecular Biology, National Cancer Institute, NIH, Building 37, Room 2E24, 37 Convent Drive, MSC 4255, Bethesda, MD 20892-4255.E-mail: gmerlino@helix.nih.gov placenta (Bladt et al, 1995; Schmidt et al, 1995; Uehara et al, 1995).

In the fetal digestive tract, c-met transcripts were found in the epithelia of the intestinal anlagen and the villi, whereas the distribution of HGF/SF RNA showed dynamic changes during mouse development by in situ hybridization (Sonnenberg et al, 1993). Immunohistochemical analysis of temporal expression revealed that both HGF/SF and c-Met could be detected between 7 and 8 weeks of gestation in human fetal digestive tissues (Kermorgant et al, 1997). These results suggest that HGF/SF-Met signaling participates in digestive system morphogenesis. Moreover, previous studies demonstrated that HGF/SF can stimulate both esophageal and gastrointestinal epithelial growth in primary cultures (Fukamachi et al, 1994; Takahashi et al, 1995). HGF/SF was also shown to enhance both intestinal mucosal repair and function in vivo (Kato et al, 1997a, 1997b; Nishimura et al, 1998). Furthermore, it was shown recently that HGF/SF stimulated gastrointestinal tyrosine kinase activity, which colocalizes with c-Met in the brush border membrane of enterocytes (Sunitha et al, 1999). Taken together, results from these studies indicate that paracrine HGF/SF stimulation may play an important role in digestive tissue development and regeneration. 
Recently, we described some of the consequences of inappropriate expression of HGF/SF using transgenic mice in which expression of a mouse HGF/SF cDNA was regulated by the mouse metallothionein (MT) gene promoter and 5'/3' genomic flanking sequences as a model system. HGF/SF transgenic mice exhibited ectopic skeletal muscle and melanocytes in the central nervous system, suggesting that HGF/SF can function as a true morphogenetic factor in vivo by regulating differentiation and/or migration of select populations of myoblasts and neural crest cells, respectively, during embryogenesis (Takayama et al, 1996). These mice also demonstrated enhanced hepatic growth (Sakata et al, 1996), renal failure (Takayama et al, 1997a), and the development of diverse histological types of tumors of both epithelial and mesenchymal origin (Otsuka et al, 1998; Takayama et al, 1997b). In this report, we describe morphologic and functional alterations appearing in the digestive tract of HGF/SF transgenic mice, and we also discuss the possible involvement of these findings in inflammatory bowel disease (IBD).

\section{Results}

High Incidence of Premature Death Caused by Intestinal Pseudo-Obstruction in HGF/SF Transgenic Mice

Nine MT-HGF/SF founder mice were generated in which the transgene broadly expressed a characteristic 2.4kb RNA transcript (Takayama et al, 1996). Based on the level of transgene expression, we chose two lines, $\mathrm{MH} 19$ and $\mathrm{MH} 37$, as representatives for detailed analysis. In both lines, expression of the MT-HGF/SF transgene was high throughout the entire digestive tract (Takayama et al, 1996) and markedly induced after treatment with drinking water containing zinc (Fig. 1A). Endogenous c-met expression was comparable between transgenic and control colons (Fig. 1B). Transgenic mice were normal at birth but frequently experienced premature mortality. In this study, we found that 33 of 67 (49\%) MH19 and 10 of 20 (50\%) MH37 mice, mostly females, died by 6 months of age (Table 1). Pregnant females were particularly susceptible to an early demise, virtually all (10 of 11 ) succumbing during or shortly after pregnancy. Of the total premature deaths, 20 of the $33 \mathrm{MH} 19(61 \%)$ and 8 of the $10 \mathrm{MH} 37$ (80\%) mice died between 8 and 15 weeks with highly distended abdomens and progressive wasting syndrome. Dissection of these moribund transgenic mice revealed distension of the gastrointestinal tract (Fig. 2C), in which the position of the transitional zone between the distended and narrow segments of the intestine varied from animal to animal. In some transgenic mice, the entire colon appeared narrow. In others, only the most distal part of the rectum was narrow, resulting in distension of the entire intestine. The narrow segment rarely spanned from the distal small intestine to the distal rectum. This phenotype is often associated with an intestinal obstruction; however, no overt mechanical obstruction was found at any site along the gastrointestinal tract. We conclude that the majority of premature deaths in these
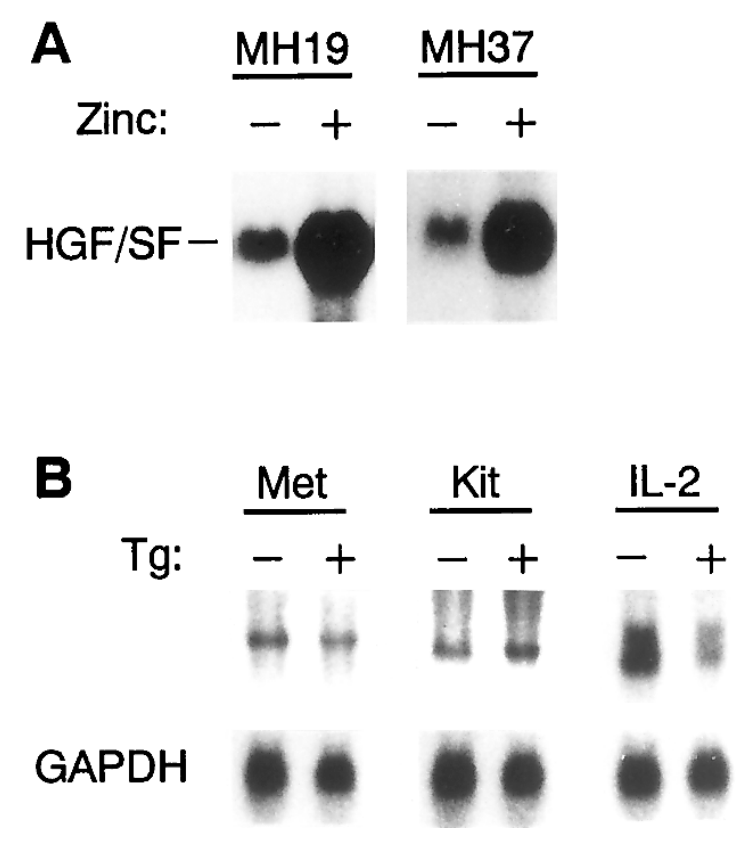

\section{Figure 1.}

Analysis of transgenic hepatocyte growth factor/scatter factor (HGF/SF), native c-met, c-kit, and interleukin-2 (IL-2) transcripts in transgenic mouse colons by Northern blot hybridization. A, HGF/SF transgene expression in distal colons from 4- to 8-week-old MH19 and MH37 transgenic mice with $(+)$ or without $(-)$ the addition of $25 \mathrm{~mm}$ zinc sulfate in the drinking water. B, Endogenous c-met, c-kit, and IL-2 expression in distal colons, including rectums, from 12-week-old control (-) and MH19 transgenic (+) female mice. Note significantly reduced expression of IL-2 in transgenic distal colon. Filters were rehybridized with a glyceraldehyde-3-phosphate dehydrogenase (GAPDH) probe to assess RNA loading and transfer variation.

HGF/SF transgenic mice was caused by sporadic intestinal obstruction of unknown etiology, which we hereafter refer to as pseudo-obstruction (Table 1). Renal failure was responsible for most of the other premature deaths (Table 1). Mortality was substantial after 6 months of age as well. Transgenic mice surviving beyond one year developed progressive renal disease and/or diverse histological types of tumors in multiple sites (Otsuka et al, 1998; Sakata et al, 1996; Takayama et al, 1997a, 1997b). Wild-type FVB/N animals demonstrated neither intestinal nor renal disease.

HGF/SF transgenic mice also frequently exhibited rectal prolapse (Fig. 2A). A reddened anus was noticeable in many of the transgenic mice as early as 3 weeks of age, and sometimes blood was found on the prolapsed rectum. In severe adult cases, the whole rectum was prolapsed (Fig. 2B). Anal glands in transgenic mice were often hyperplastic and/or cystic, perhaps contributing to this phenotype.

\section{Histological Analysis of the Digestive Tract in HGF/SF Transgenic Mice}

Microscopically, the stomach and small intestine appeared normal in HGF/SF transgenic mice, irrespective of the presence of the distension phenotype. However, vertical sections of the bowel frequently illustrated a pronounced thickening of the rectal wall, 
Table 1. Incidence of Premature Death Associated with Intestinal Pseudo-Obstruction, Renal Failure, and Pregnancy in HGF/SF Transgenic Mice

\begin{tabular}{|c|c|c|c|c|c|c|}
\hline & \multicolumn{3}{|c|}{ Line MH19 } & \multicolumn{3}{|c|}{ Line MH37 } \\
\hline & Male (\%) & Female (\%) & Total (\%) & Male (\%) & Female $(\%)$ & Total (\%) \\
\hline Premature death ${ }^{a}$ & 8/32 (25) & 25/35 (71) & $33 / 67$ (49) & $1 / 10(10)$ & $9 / 10(90)$ & $10 / 20(50)$ \\
\hline Pseudo-obstruction $b$ & $4 / 8 \quad(50)$ & $16 / 25(64)$ & $20 / 33(61)$ & $0 / 1 \quad(0)$ & $8 / 9 \quad$ (89) & $8 / 10(80)$ \\
\hline Renal failure ${ }^{c}$ & $4 / 8 \quad(50)$ & $9 / 25(36)$ & $13 / 33(39)$ & $0 / 1 \quad(0)$ & $1 / 9$ & $1 / 10(10)$ \\
\hline Pregnancy-related ${ }^{d}$ & & $7 / 7(100)$ & & & $3 / 4 \quad(75)$ & \\
\hline
\end{tabular}

HGF/SF, hepatocyte growth factor/scatter factor.

${ }^{a}$ Total number of analyzable transgenic mice from lines MH19 or MH37 exhibiting premature death, defined here as mice dying at $\leq 6$ months of age.

${ }^{b}$ Number of transgenic mice that died of intestinal pseudo-obstruction relative to total number of premature deaths; this lesion occurred most frequently in mice between 8 and 15 weeks of age.

${ }^{c}$ Number of transgenic mice that died of renal failure relative to total number of premature deaths.

${ }^{d}$ Number of pregnant transgenic mice that died relative to total number of pregnant animals. The 10 mice in this study, combined from lines MH19 and MH37, died during or shortly after lactation of either obstruction (six) or renal failure (four). The increased incidence of premature death in pregnant females may be related to the impact of hormonal changes on the transgenic abdomen.

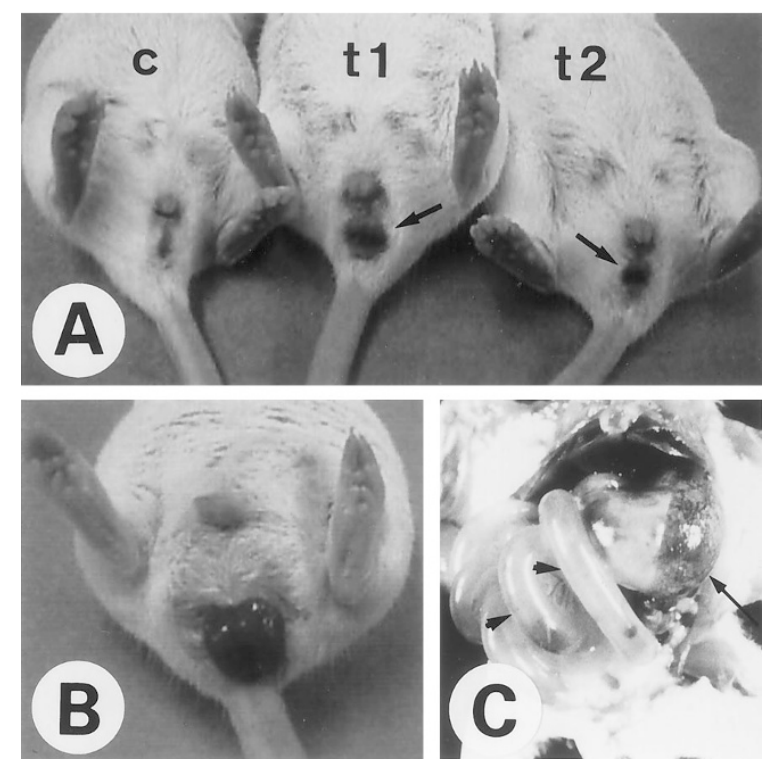

Figure 2.

Anorectal prolapse and intestinal pseudo-obstruction in HGF/SF transgenic mice. A, Gross morphological features of anal phenotypes of 8-week-old control (c) and MH19 transgenic (t1 and t2) female mice. Arrows indicate anorectal prolapses in mild (t2) and moderate (t1) cases compared with control (c) normal anus. B, Complete anorectal prolapse in a 10-month-old MH19 transgenic male mouse. C, Intestinal pseudo-obstruction observed in 9-week-old MH19 transgenic female mouse. Note markedly distended stomach (arrow) and small intestine (arrowheads).

especially at the anorectal junction (Fig. 3, A to D). The crypts were elongated and showed evidence of proliferation (data not shown). In severe cases there was distortion of the crypts, including branching and cystic dilation (Fig. 3D). Frequently, crypt abscesses (crypts containing a neutrophilic infiltrate) were identified (Fig. $3 \mathrm{E})$. A mixed inflammatory cell infiltrate, consisting of lymphocytes, plasma cells, and neutrophilic granulocytes was moderately present in the lamina propria. Mucosal ulcerations were occasionally observed at the very end of the rectum (Fig. 3F). This ulcerative proctitis, which developed with high penetrance, appeared to arise by a mechanism independent of the aforementioned intestinal pseudo-obstruction, which appeared sporadically and at sites distinct from the rectal thickening. In human patients, toxic megacolon associated with ulcerative colitis (UC) usually occurs with pancolitis and does not affect the small intestine (Sheth and LaMont, 1998). Because intestinal inflammation in HGF/SF transgenic mice was limited to the rectum and dilation often extended over the small intestine, the intestinal pseudo-obstruction is not consistent with UC-related toxic megacolon.

Because HGF/SF transgenic mice were shown to exhibit abnormalities in neural crest development (Takayama et al, 1996), and because a variety of spontaneous and gene-targeted mouse mutants and patients with Hirschprung's disease show intestinal obstruction associated with aberrant development of myenteric ganglia (Baynash et al, 1994; Hosoda et al, 1994; Schuchardt et al, 1994), we evaluated the condition of such ganglia within the intestinal tracts of adult transgenic mice and their wild-type littermates. A $\mathrm{D} \beta \mathrm{H}$-nlacZ transgene was bred into the HGF/SF transgenic colony to provide a useful marker of ganglion cell nuclei that could be visualized by histochemical staining of whole-mount preparations (Kapur et al, 1992). However, no differences in the number or the distribution of enteric ganglion cells were identified between HGF/SF, D $\beta \mathrm{H}$-nlacZ double-transgenic mice and their $\mathrm{D} \beta \mathrm{H}$-nlacZ single-transgenic littermates (Fig. 4A). Similarly, whole-mount analysis of myenteric plexus architecture by acetylcholinesterase histochemical staining and light microscopic studies of transverse and longitudinal histological sections failed to reveal any differences between HGF/SF transgenic mice and their littermates (Fig. 4, B to E). Included in the latter studies were asymptomatic transgenic animals as well as mice with external and internal gross anatomic signs of intestinal dysmotility (ie, abdominal distension and marked small intestinal distension). These data support the notion that HGF/SF transgenic mice develop an intestinal pseudo-obstruction, which was not due to aganglionosis or another resolvable malformation/degeneration of the enteric nervous system or to the intestinal smooth muscle, which was histologically indistinguishable from wild type. 

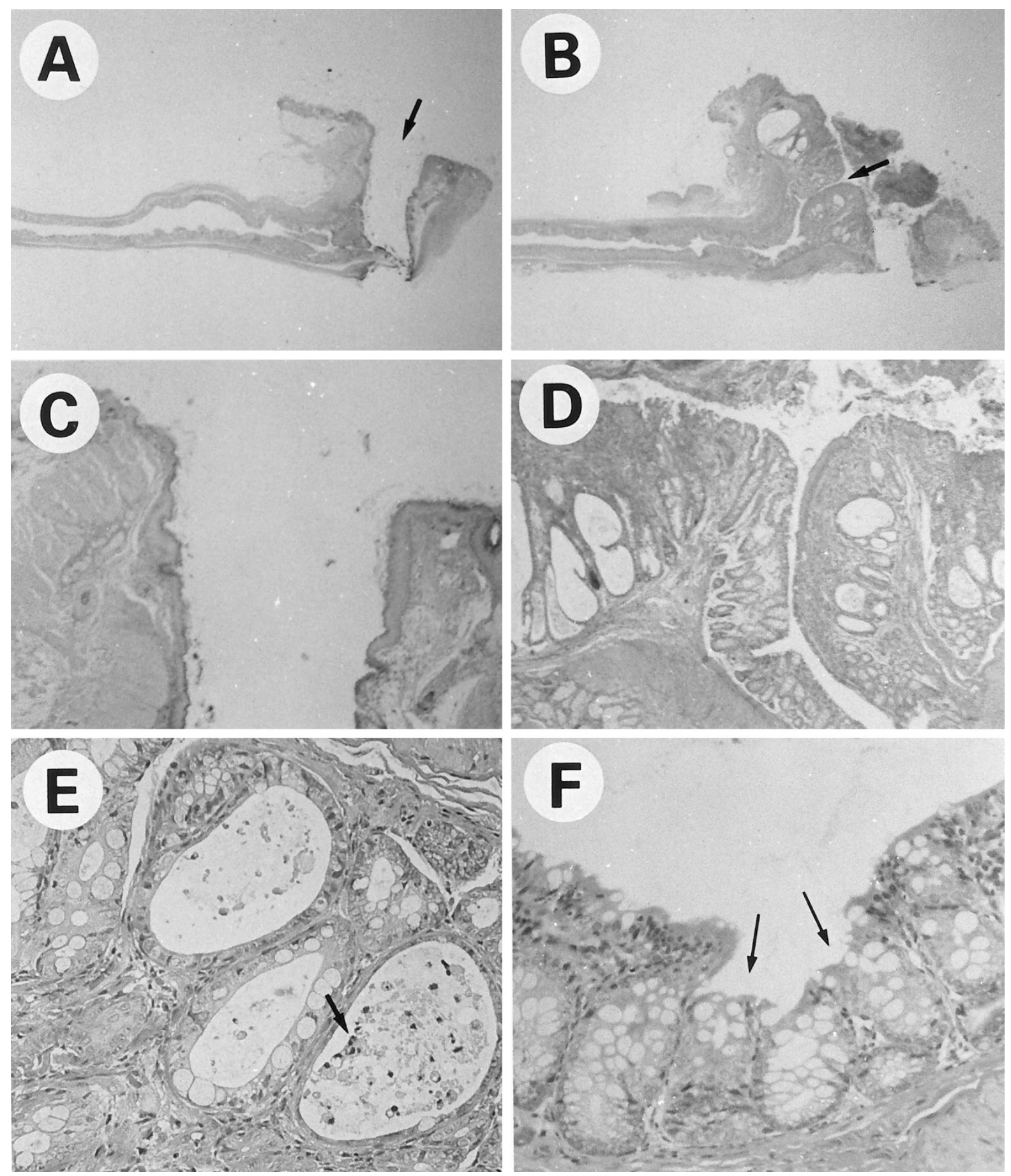

\section{Figure 3.}

Histological analysis of inflammatory bowel disease (IBD) in the terminal colon and rectum of HGF/SF transgenic mice. A low-power view of vertical section of the terminal colon and rectum in a 8-week-old MH19 transgenic female mouse (B) and a control sibling (A). Note the thickened wall in the transgenic rectum (B). Arrows indicate anal canals. C and D, A high-power view of anorectal junctions of the same animals as in (A) and (B), respectively. The rectal wall is markedly thickened, and the crypts are elongated and distorted in the transgenic mouse (D). E, Crypt abscess represents a neutrophic infiltrate inside the lumen of crypts (arrow). F, Mucosal ulceration accompanied by mixed inflammatory cell infiltrate in the lamina propria (arrows). A and C, Control FVB/N mouse. B, D, E, and F, MH19 HGF/SF transgenic mouse. Original magnifications: $A$ and $B, \times 10 ; C$ and $D, \times 40 ; E, \times 400 ; F, \times 200$.

\section{Expression of Interleukin-2 and c-kit in the Large Intestine of HGF/SF Transgenic Mice}

Because overt anatomical changes in the HGF/SF transgenic intestine were lacking, we speculated that the observed pseudo-obstruction was due to func- tional dysmotility. Based on reports that the receptor tyrosine kinase encoded by the c-kit proto-oncogene is required for development of the interstitial cells of Cajal (ICC), which have been implicated as part of the intestinal pacemaker system (Hulzinga et al, 1995; 

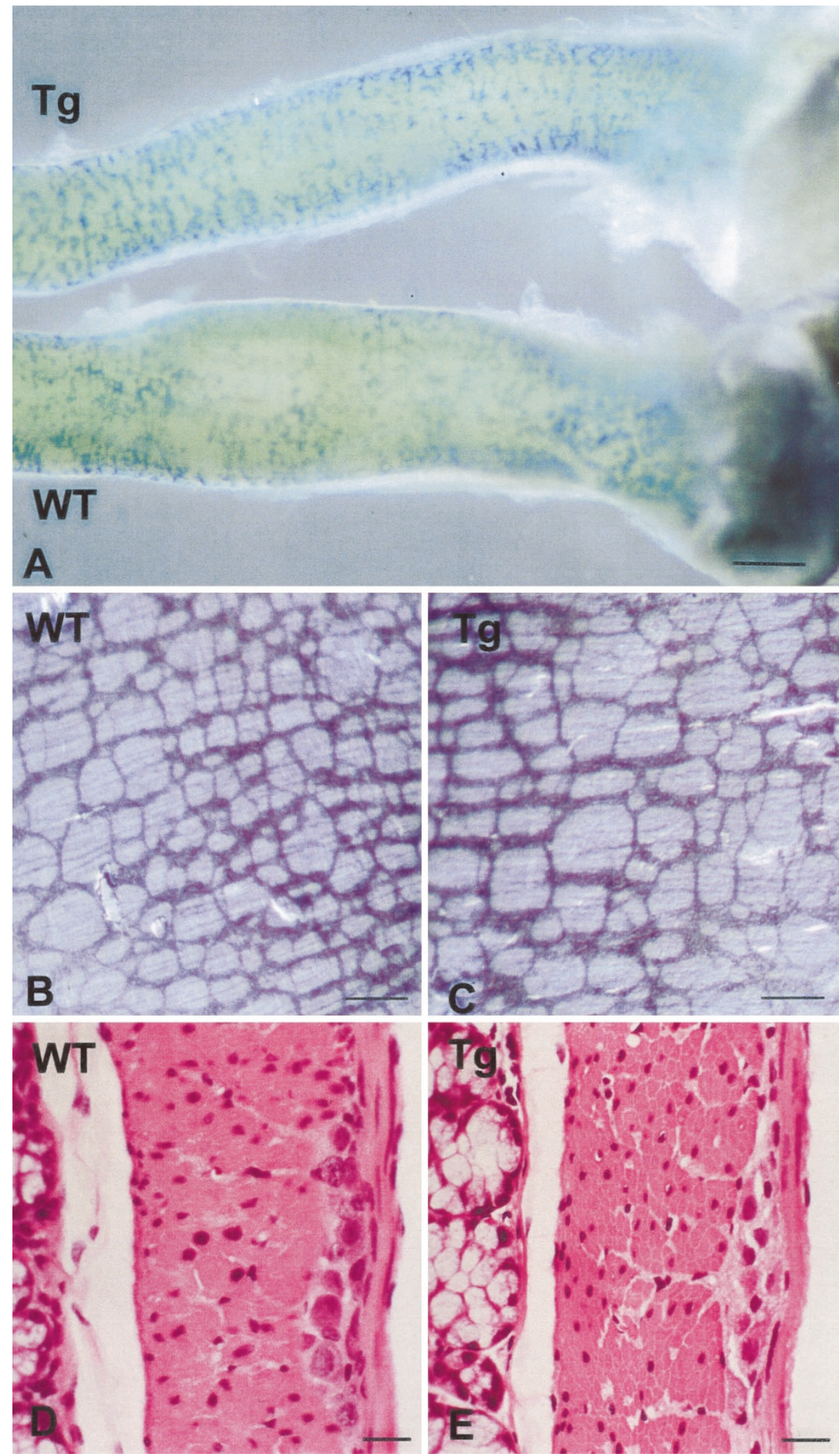

\section{Figure 4.}

Lack of neuromuscular pathology in intestinal tracts of HGF/SF transgenic mice. A, X-gal-stained terminal colons of a HGF/SF, D $\beta$ H-nlacZ double-transgenic mouse (top), and its $\mathrm{D} \beta \mathrm{H}$-nlacZ single-transgenic littermate (bottom) show similar uniform distributions of ganglion cell nuclei. B and $\mathrm{C}$, Acetylcholinesterase-stained whole-mount preparations of mid-large intestine from a HGF/SF transgenic mouse (C) and its littermate (B) illustrate the normal two-dimensional architecture of the myenteric plexus that was associated with both genotypes. D and E, Photomicrographs of hematoxylin-and-eosin stained longitudinal sections of mid-large intestine from a symptomatic HGF/SF transgenic mouse (E) and its littermate (D) show nearly identical features. The only differences between the two are attributable to differences in tissue shrinkage, partially related to segment distension at the time of fixation. Scale bars: A, $800 \mu \mathrm{m} ; \mathrm{B}$ and $\mathrm{C}, 100 \mu \mathrm{m} ; \mathrm{D}$ and E, $50 \mu \mathrm{m}$. 
Maeda et al, 1992; Torihashi et al, 1995; Ward et al, 1998; Yamataka et al, 1998), we examined c-kit expression in the distal colon of HGF/SF transgenic mice by Northern blot analysis. The level of c-kit expression in the transgenic colon was essentially equal to that in wild-type mice (Fig. 1B), indicating that intestinal pseudo-obstruction was likely caused by a mechanism other than altered c-kit expression or significant loss of ICC.

It has been shown that gene-targeted disruption of the cytokine genes, interleukin-2 (IL-2) and interleukin-10 (IL-10), produced mice that developed intestinal lesions similar to those of human inflammatory bowel disease (IBD) (Kühn et al, 1993; Sadlack et al, 1993). We therefore examined expression of IL-2 and IL-10 RNA transcripts in the distal colon, including the rectum, where IBD-like phenotypic changes were observed in the absence of pseudo-obstruction. There was no significant difference in IL-10 expression between the transgenic and wildtype colon (data not shown). In contrast, the IL-2 expression level was markedly reduced in the colons of HGF/SF transgenic mice, raising the possibility that insufficient amounts of IL-2 may contribute to the induction of chronic rectal inflammation in the HGF/SF transgenic mouse (Fig. 1B).

\section{Discussion}

Growth factors and their receptors play important roles in cell proliferation, migration, wound repair, and ulcer healing. Under normal conditions, cell populations within the gastrointestinal tract are maintained in a dynamic state because cell loss through exfoliation of surface cells is balanced by a continuous cell renewal. The balance between cell loss and renewal in the digestive tract, often upset in the pathologic state, appears to be tightly regulated by several growth factors including those of the epidermal growth factor (EGF) family, the transforming growth factor beta (TGF- $\beta$ ) family, the insulin-like growth factor (IGF) family, and the fibroblast growth factor (FGF) family (Jones et al, 1999). The role of HGF/SF in digestive tract disorders has not been as well characterized. Previous studies have shown that expression of HGF/SF and C-MET mRNA among UC and control patients was comparable (Chowdhury et al, 1996). In contrast, serum HGF/SF levels in patients with IBD were higher than those in healthy individuals (Matsuno et al, 1997). In this study we use a transgenic mouse model to show that inappropriate expression of HGF/SF can induce both sporadic intestinal pseudoobstruction and a rectal IBD. This animal model has the potential to elucidate mechanisms regulating intestinal motility and mucosal protection in patients.

Severe intestinal dysmotility can be caused by congenital enteric aganglionosis in humans with Hirschsprung's disease and in a variety of spontaneous and gene-targeted mouse mutants, including RET, GDNF, endothelin-3, endothelin-B receptor, and SOX10 null mutations (Baynash et al, 1994; Hosoda et al, 1994; Moore et al, 1996; Pichel et al, 1996; Pingault et al, 1998; Sanchez et al, 1996; Schuchardt et al, 1994). As enteric ganglia in the HGF/SF transgenic intestine are intact, the pathogenesis is different from that operating in Hirschsprung's disease. Instead, HGF/SF transgenic mice represent a new model of intestinal pseudo-obstruction, a rare disorder in which impaired intestinal motility leads to Hirschsprung's disease-like symptoms, but ganglion cells are present throughout the entire alimentary tract. The origins of pseudoobstruction are heterogeneous and often obscure (Krishnamurthy and Schuffler, 1987). Some forms are characterized by degenerative changes in enteric neurons or smooth muscle that were not observed in HGF/SF transgenic mice. Another subset of patients and animal models have subtle changes in enteric ganglion cell number or other cell types that could not be excluded by the methods used in our study. This includes patients with chronic obstructive symptoms and reduced numbers of ICC, modified smooth muscle cells that function as a "pacemaker" system for the intestinal tract (Faussone-Pellegrini et al, 1999a, 1999b; Yamataka et al, 1998). Although it is unclear whether changes evident in the ICC of the latter group are primary or secondary to underlying obstructive symptoms, mutations that impair expression of c-kit receptor by ICC lead to loss of these cells and intestinal dysmotility in mice. Although impaired ICC function has not been excluded in HGF/SF transgenic mice, we found no difference in the levels of c-kit mRNA in transgenic colon compared to wild type. At present, like many pseudo-obstruction patient/animal models, HGF/SF transgenic mice lack any recognized neuromuscular pathology and are presumed to result from physiological defects in the enteric nervous system or smooth muscle. However, given that the HGF/SF receptor, c-Met, is expressed in gastrointestinal epithelium, it remains a possibility that impaired motility in these transgenic animals is due to altered epithelial function resulting in increased fecal viscosity.

$\mathrm{UC}$ is a chronic, presumably noninfectious, inflammation limited to the large intestine. In approximately one quarter of UC patients the disease is limited to the rectum (proctitis). The major working hypothesis concerning the pathogenesis of $U C$ is that the disease is due to an abnormal and uncontrolled immune response to one or more normally occurring gut constituents. Previous studies have shown that genetargeted disruption of either of the genes encoding the cytokines IL-2 and IL-10, the T cell receptor genes, or the mdr1a gene creates mice that develop UC-like intestinal lesions similar to those of human IBD (Kühn et al, 1993; Mombaerts et al, 1993; Panwala et al, 1998; Sadlack et al, 1993). It is notable that IL-2 expression is decreased in the colon of HGF/SF transgenic mice exhibiting IBD without pseudoobstruction. Growth factors regulate a wide spectrum of processes which include protection of the intestinal mucosa and activation and regulation of the intestinal immune system. It has been speculated that human IBD is a disease of multigenic etiology (Beck and Podolsky, 1999). An IL-2 deficiency caused by forced HGF/SF expression in the transgenic colon may induce inflammatory responses leading to IBD. In fact, 
HGF/SF transgenic mice frequently develop anorectal prolapse, found in both IL-2-deficient and $\mathrm{T}$ cell receptor mutant mice that develop UC-like IBD. It remains to be determined whether the observed rectal pathology results directly from HGF/SF overexpression or from the complex deregulation of the immune system caused by the associated IL-2 deficiency. It would be illuninating to cross IL-2 transgenic mice with HGF/SF transgenic mice to determine if IL-2 overexpression can rescue the phenotypes seen in the HGF/SF transgenic colon.

In conclusion, we have determined that inappropriate expression of HGF/SF in the digestive tract of mice can induce intestinal pseudo-obstruction of unknown etiology and ulcerative proctitis associated with diminished IL-2 expression. These findings suggest a possible role for HGF/SF, not only in gastrointestinal motility, but also in epithelial repair and mucosal protection. HGF/SF may contribute to a fraction of IBD by influencing the local production of cytokines that constitute the intestinal immune system. Although HGF/SF has been applied therapeutically in the treatment of patients with, for example, peripheral arterial disease (Morishita et al, 1999) or liver cirrhosis (Ueki et al, 1999), the correlation of chronic elevated HGF/SF exposure with a high incidence of premature death in transgenic mice associated with both gastrointestinal disease, shown here, as well as renal failure, reported earlier (Takayama et al, 1997a), demonstrates the potential liability in the use of HGF/SF in a clinical context. The HGF/SF transgenic mouse model may provide fresh insights into pathogenic mechanisms associated with the gastrointestinal disease process and facilitate the exploration of prospects for prevention and therapeutic intervention.

\section{Materials and Methods}

\section{Animals}

Transgenic mice harboring a mouse HGF/SF cDNA under the control of the mouse MT gene promoter and $51 / 3^{\prime}$ flanking sequences (Palmiter et al, 1993) were generated on a FVB/N genetic background as previously described (Takayama et al, 1996). Where indicated, the MT transgene promoter was maximally induced by maintaining mice on drinking water containing $25 \mathrm{~mm}$ zinc sulfate; however, exposure to zinc was not required for the development of gastrointestinal phenotypes. Two independently derived lines of HGF/SF transgenic mice, MH19 and MH37, were used in these studies. The criteria for intestinal pseudoobstruction was the presence of symptoms and signs of intestinal obstruction with no mechanical obstruction or chronic constipation, excluding Hirschsprung's disease (Faure et al, 1999). Animals used in this specific study were kept in a facility devoid of all pathogens except the spiral-shaped bacterium Helicobacter. Although intestinal microflora can influence the pathogenesis of intestinal inflammation and prolapse, we have observed the same spectrum of gastrointestinal phenotypes in other Helicobacter-free HGF/SF transgenic animals. All animal studies were performed in accordance with the guidelines for animal care and use established by the National Institutes of Health (NIH).

\section{Analysis of RNA}

HGF/SF and c-met transcripts were detected by Northern blot hybridization using a PCR-generated probe (Takayama et al 1996, 1997b). Total RNA was prepared using guanidine thiocyanate as previously described (Jhappan et al, 1990), and $20 \mu \mathrm{g}$ were loaded per lane onto an agarose gel and transferred to nylon membranes after electrophoresis. A mouse c-kit cDNA probe was generated by PCR using the pUC kit EH1 clone (RIKEN Gene Bank, Tsukuba, Japan) as a template and the following set of primers: 5'- GTAAAACGACGGCCAGT -3' and 5'- CAGGAAACAGCTATGAC -3'. A mouse IL-2 probe was synthesized by PCR using the pBluescriptSKII+mIL-2 clone (RIKEN Gene Bank) and the following primer set: 5'- ATTAACCCTCACTAAAGG -3' and 5'- AATACGACTCACTATAGG -3'. To control for RNA loading and transfer variation, filters were routinely rehybridized with a glyceraldehyde-3-phosphate dehydrogenase (GAPDH) probe. In case of IL-2, the final wash of the hybridized filter was performed under highly stringent conditions to avoid nonspecific signals from repetitive sequences.

\section{Histology and Evaluation of Enteric Neuromuscular Anatomy}

Colons and small intestinal segments from adult HGF/SF transgenic mice and their nontransgenic littermates were routinely fixed in $10 \%$ buffered formalin, paraffin-embedded, sectioned, and stained with hematoxylin and eosin. Sections were examined under bright-field microscopy with an Olympus model $\mathrm{BH}-2$ photomicroscope (Olympus, Tokyo, Japan).

HGF/SF transgenic mice were bred with $\mathrm{D} \beta \mathrm{H}$-nlacZ transgenic mice (Kapur et al, 1992) to study the relative density and distribution of enteric ganglion cell bodies in whole-mount preparation of gastrointestinal tracts. Adult HGF/SF, D $\beta \mathrm{H}$-nlacZ double-transgenic mice, and their $\mathrm{D} \beta \mathrm{H}-\mathrm{nlacZ}$ single-transgenic littermates were euthanized by $\mathrm{CO}_{2}$ asphyxiation, and their small and large intestines were resected. The tissues were fixed by immersion in 10\% neutral buffered formalin ( 2 hours, $4^{\circ} \mathrm{C}$ ), rinsed briefly with $0.1 \mathrm{M}$ phosphate buffer ( $\mathrm{pH} 7.4, \mathrm{~PB})$, and incubated overnight in $0.1 \mathrm{M}$ PB containing $5 \mathrm{~mm} \mathrm{FeCN}$ and $5 \mathrm{~mm} \mathrm{FeCN}_{2}$. After postfixation in $10 \%$ formalin for 2 hours, the distribution of ganglion cell nuclei was studied and photographed using a dissection microscope.

Whole-mount histochemical staining for acetylcholinesterase activity in resected colons was performed as follows. Adult colons were fixed in $4 \%$ paraformaldehyde $\left(4^{\circ} \mathrm{C}, 2\right.$ hours), equilibrated in $30 \%$ sucrose overnight at $4^{\circ} \mathrm{C}$, rinsed in $\mathrm{PB}$, immersed for 5 minutes in $3 \% \mathrm{H}_{2} \mathrm{O}_{2}$, and stained as described previously (Baljet and Drukker, 1975). The stained tissue was rinsed in $\mathrm{PB}$ and enhanced by 5 minutes incubation in 0.05 M Tris- $\mathrm{Cl}$ ( $\mathrm{pH} 8.0$ ) containing 0.05\% diaminoben- 
zidine and $0.8 \% \mathrm{NiCl}_{2} \cdot \mathrm{H}_{2} \mathrm{O}_{2}(0.03 \%)$ was added to the reaction, and the sample was monitored for color transformation (1-5 minutes).

\section{Acknowledgements}

We thank Dr. Hirofumi Hamada for the pBluescript SKII+mIL-2 clone, Dr. Richard Palmiter for the MT locus control region clones, Dr. Miriam Anver for assistance with histopathology, and Drs. Norio Horiguchi and Mitsuo Toyoda for the breeding and maintenance of the transgenic mice.

\section{References}

Baljet B and Drukker J (1975). An acetylcholinesterase method for in toto staining of peripheral nerves. Stain Technol 50:31-36.

Baynash AG, Hosoda K, Giaid A, Richardson JA, Emoto N, Hammer RE, and Yanagisawa M (1994). Interaction of endothelin-3 with endothelin-B receptor is essential for development of epidermal melanocytes and enteric neurons. Cell 79:1277-1285.

Beck PL and Podolsky DK (1999). Growth factors in inflammatory bowel disease. Inflamm Bowel Dis 5:44-60.

Bladt F, Riethmacher D, Isenmann S, Aguzzi A, and Birchmeier C (1995). Essential role for the c-met receptor in the migration of myogenic precursor cells into the limb bud. Nature 376:768-771.

Chowdhury A, Fukuda R, and Fukumoto S (1996). Growth factor mRNA expression in normal colorectal mucosa and in uninvolved mucosa from ulcerative colitis patients. J Gastroenterol 31:353-360.

Faure C, Goulet O, Ategbo S, Breton A, Tounian P, Ginies JL, Roquelaure B, Despres C, Scaillon M, Maurage C, Paquot I, Hermier M, De Napoli S, Dabadie A, Huet F, Baudon JJ, and Larchet M (1999). The French-speaking group of pediatric gastroenterology. Chronic intestinal pseudoobstruction syndrome. Dig Dis Sci 44:953-959.

Faussone-Pellegrini MS, Fociani P, Buffa R, and Basilisco G (1999a). Loss of interstitial cells and a fibromuscular layer on the luminal side of the colonic circular muscle presenting as megacolon in the adult patient. Gut 45:775-779.

Faussone-Pellegrini MS, Infantino A, Matini $P$, Masin A, Mayer B, and Lise M (1999b). Neuronal anomalies and normal muscle morphology at the hypomotile ileocecocoIonic region of patients affected by idiopathic chronic constipation. Histol Histopathol 14:1119-1134.

Fukamachi H, Ichinose M, Tsukada S, Kakei N, Suzuki T, Miki K, Kurokawa K, and Masui T (1994). Hepatocyte growth factor region specifically stimulates gastro-intestinal epithelial growth in primary culture. Biochem Biophys Res Commun 205:1445-1451.

Gherardi E and Stoker M (1991). Hepatocyte growth factorscatter factor: Mitogen, motogen, and met. Cancer Cells 3:227-232.

Gohda E, Tsubouchi H, Nakayama H, Hirono S, Sakiyama O, Takahashi K, Miyazaki H, Hashimoto S, and Daikuhara Y (1988). Purification and partial characterization of hepatocyte growth factor from the plasma of a patient with fulminant hepatic failure. J Clin Invest 81:414-419.
Hosoda K, Hammer RE, Richardson JA, Baynash AG, Cheung JC, Giaid A, and Yanagisawa M (1994). Targeted and natural (piebald-lethal) mutations of endothelin-B receptor gene produce megacolon associated with spotted coat color in mice. Cell 79:1267-1276.

Hulzinga JD, Thuneberg L, Krüppel M, Malysz J, Mikkelsen $\mathrm{HB}$, and Bernstein A (1995). W/kit gene required for intestinal cells of Cajal and for intestinal pacemaker activity. Nature 373:347-349.

Jhappan C, Stahle C, Harkins RN, Fausto N, Smith GH, and Merlino GT (1990). TGF $\alpha$ overexpression in transgenic mice induces liver neoplasia and abnormal development of the mammary gland and pancreas. Cell 61:1137-1146.

Jones MK, Tomikawa M, Mohajer B, and Tarnawski AS (1999). Gastrointestinal mucosal regeneration: Role of growth factors. Front Biosci 4:D303-D309.

Kapur RP, Yost C, and Palmiter RD (1992). A transgenic model for studying development of the enteric nervous system in normal and aganglionic mice. Development 116:167-175.

Kato Y, Yu D, Lukish JR, and Schwartz MZ (1997a). Hepatocyte growth factor enhances intestinal mucosal cell function and mass in vivo. J Pediatr Surg 32:991-994.

Kato Y, Yu D, Lukish JR, and Schwartz MZ (1997b). Influence of luminal hepatocyte growth factor on small intestine mucosa in vivo. J Surg Res 71:49-53.

Kermorgant S, Walker F, Hormi K, Dessirier V, Lewin MJM, and Lehy T (1997). Developmental expression and functionality of hepatocyte growth factor and c-Met in human fetal digestive tissues. Gastroenterology 112:1635-1647.

Krishnamurthy S and Schuffler MD (1987). Pathology of neuromuscular disorders of the small intestine and colon. Gastroenterology 93:610-639.

Kühn R, Löhler J, Rennick D, Rajewsky K, and Müller W (1993). Interleukin-10-deficient mice develop chronic enterocolitis. Cell 75:263-274.

Maeda H, Yamagata A, Nishikawa S, Yoshinaga K, Kobayashi S, Nishi K, and Nishikawa S (1992). Requirement of c-kit for development of intestinal pacemaker system. Development 116:369-375.

Matsuno M, Shiota G, Umeki K, Kawasaki H, Kojo H, and Miura K (1997). Clinical evaluation of hepatocyte growth factor in patients with gastrointestinal and pancreatic diseases with special reference to inflammatory bowel disease. Res Commun Mol Pathol Pharmacol 97:25-37.

Mombaerts P, Mizoguchi E, Grusby MJ, Glimcher LH, Bhan AK, and Tonegawa S (1993). Spontaneous development of inflammatory bowel disease in T cell receptor mutant mice. Cell 75:274-282.

Montesano R, Matsumoto K, Nakamura T, and Orci L (1991). Identification of a fibroblast-derived epithelial morphogen as hepatocyte growth factor. Cell 67:901-908.

Moore MW, Klein RD, Farinas I, Sauer H, Armanini M, Phillips H, Reichardt LF, Ryan AM, Carver-Moore K, and Rosenthal A (1996). Renal and neuronal abnormalities in mice lacking GDNF. Nature 382:76-79.

Morishita R, Nakamura S, Hayashi S, Taniyama Y, Moriguchi A, Nagano T, Taiji M, Noguchi H, Takeshita S, Matsumoto K, Nakamura T, Higaki J, and Ogihara T (1999). Therapeutic angiogenesis induced by human recombinant hepatocyte growth factor in rabbit hind limb ischemia model as 
cytokine supplement therapy. Hypertension 33:13791384.

Nakamura T, Nishizawa T, Hagiya M, Seki T, Shimonishi M, Sugimura A, Tashiro K, and Shimizu S (1989). Molecular cloning and expression of hepatocyte growth factor. Nature 342:440-443.

Nishimura S, Takahashi M, Ota S, Hirano M, and Hiraishi H (1998). Hepatocyte growth factor accelerates restitution of intestinal epithelial cells. J Gastroenterol 33:172-178.

Otsuka T, Takayama H, Sharp R, Celli G, LaRochelle WJ, Bottaro DP, Ellmore N, Vieira W, Owens JW, Anver M, and Merlino G (1998). c-Met autocrine activation induces development of malignant melanoma and acquisition of the metastatic phenotype. Cancer Res 5157-5167.

Palmiter RD, Sandgren EP, Koeller DM, and Brinster RL (1993). Distal regulatory elements from the mouse metallothionein locus stimulate gene expression in transgenic mice. Mol Cell Biol 13:5266-5275.

Panwala CM, Jones JC, and Viney JL (1998). A novel model of inflammatory bowel disease: Mice deficient for the multiple drug resistance gene, mdrla, spontaneously develop colitis. J Immunol 161:5733-5744.

Pichel JG, Shen L, Sheng HZ, Granholm AC, Drago J, Grinberg A, Lee EJ, Huang SP, Saarma M, Hoffer BJ, Sariola H, and Westphal H (1996). Defects in enteric innervation and kidney development in mice lacking GDNF. Nature 382:73-76.

Pingault V. Boudurand N, Kuhlbrodt K, Goerich DE, Prehu MO, Puliti A, Herbarth B, Hermans-Borgmeyer I, Legius E, Matthijs G, Amiel J, Lyonnet S, Ceccherini I, Romeo G, Smith JC, Read AP, Wegner M, and Goossens M (1998). SOX10 mutations in patients with Waardenburg-Hirschsprung disease. Nat Genet 18:171-173.

Rosen EM, Nigam SK, and Goldberg ID (1994). Scatter factor and the c-Met receptor: A paradigm for mesenchymal/ epithelial interaction. J Cell Biol 127:1783-1787.

Rubin JS, Chan AML, Bottaro DP, Burgess WH, Taylor WG, Cech AC, Hirschfield DW, Wong J, Miki T, Finch PW, and Aaronson SA (1991). A broad spectrum human lung fibroblast-derived mitogen is a variant of hepatocyte growth factor. Proc Natl Acad Sci USA 88:415-419.

Sadlack B, Merz H, Schorie H, Schimpl A, Feller AC, and Horak I (1993). Ulcerative colitis-like disease in mice with a disrupted interleukin-2 gene. Cell 75:253-261.

Sakata H, Takayama H, Sharp R, Rubin JS, Merlino G, and LaRochelle WJ (1996). Hepatocyte growth factor/scatter factor overexpression induces growth, abnormal development and tumor formation in transgenic mouse livers. Cell Growth Differ 7:1513-1523.

Sanchez MP, Silos-Santiago I, Frisen J, He B, Lira SA, and Barbacid M (1996). Renal agenesis and the absence of enteric neurons in mice lacking GDNF. Nature 382:70-73.

Schmidt C, Bladt F, Goedecke S, Brinkman V, Zschiesche W, Sharpe M, Gherardi E, and Birchmeier C (1995). Scatter factor/hepatocyte growth factor is essential for liver development. Nature 373:699-702.

Schuchardt A, D'Agati V, Larsson-Blomberg L, Costantini F, and Pachnis V (1994). Defects in the kidney and enteric nervous system of mice lacking the tyrosine kinase receptor Ret. Nature 367:380-383.
Sheth SG and LaMont JT (1998). Toxic megacolon. Lancet 351:509-513.

Sonnenberg E, Meyer D, Weidner KM, and Birchmeier C (1993). Scatter factor/hepatocyte growth factor and its receptor, the c-met tyrosine kinase, can mediate a signal exchange between mesenchyme and epithelia during mouse development. J Cell Biol 123:223-235.

Sunitha I, Shen R, McKillop IH, Lee JH, Resau J, and Avigan $M$ (1999). A src-related kinase in the brush border membranes of gastrointestinal cells is regulated by c-met. Exp Cell Res 250:86-98.

Takahashi M, Ota S, Ogura K, Nakamura T, and Omata M (1995). Hepatocyte growth factor stimulates wound repair of the rabbit esophageal epithelial cells in primary culture. Biochem Biophys Res Commun 215:298-305.

Takayama H, LaRochelle WJ, Anver M, Bockman DE, and Merlino G (1996). Scatter factor/hepatocyte growth factor as a regulator of skeletal muscle and neural crest development. Proc Natl Acad Sci USA 93:5866-5871.

Takayama H, LaRochelle WJ, Sabnis SG, Otsuka T, and Merlino G (1997a). Renal tubular hyperplasia, polycystic disease, and glomerulosclerosis in transgenic mice overexpressing hepatocyte growth factor/scatter factor. Lab Invest 77:131-138.

Takayama H, LaRochelle WJ, Sharp R, Otsuka T, Kriebel P, Anver M, Aaronson SA, and Merlino G (1997b). Diverse tumorigenesis associated with aberrant development in mice overexpressing hepatocyte growth factor/scatter factor. Proc Natl Acad Sci USA 94:701-706.

Torihashi S, Ward SM, Nishikawa S, Nishi K, Kobayashi S, and Sanders KM (1995). c-kit-dependent development of interstitial cells and electrical activity in the murine gastrointestinal tract. Cell Tissue Res 280:97-111.

Uehara Y, Minowa O, Mori C, Shiota K, Kuno J, Noda T, and Kitamura N (1995). Placental defect and embryonic lethality in mice lacking hepatocyte growth factor/scatter factor. Nature 373:702-705.

Ueki T, Kaneda Y, Tsutsui H, Nakanishi K, Sawa Y, Morishita R, Matsumoto K, Nakamura T, Takahashi H, Okamoto E, and Fujimoto J (1999). Hepatocyte growth factor gene therapy of liver cirrhosis in rats. Nat Med 5:226-230.

Vande Woude GF (1992). Hepatocyte growth factor: Mitogen, motogen, and morphogen. Jpn J Cancer Res 83: cover article.

Ward SM, Morris G, Reese L, Wang X-Y, and Sanders KM (1998). Interstitial cells of Cajal mediate enteric inhibitory neurotransmission in the lower esophageal and pyloric sphincters. Gastroenterology 115:314-329.

Yamataka A, Ohshiro K, Kobayashi H, Lane GJ, Yamataka T, Fujiwara T, Sunagawa M, and Miyano T (1998). Abnormal distribution of intestinal pace maker (C-KIT-positive) cells in an infant with chronic idiopathic intestinal pseudoobstruction. J Pediatr Surg 33:859-862.

Zarnegar R and Michalopoulos GK (1995). The many faces of hepatocyte growth factor: From hepatopoiesis to hematopoiesis. J Cell Biol 129:1177-1180. 